\title{
Barriers to End-of-Life Services for Persons Experiencing Homelessness as Perceived by Health and Social Service Providers
}

Meredith MacKenzie, MD, BSc, CCFP (AM), FCFP and Eva Purkey, MD, MPH, CCFP, FCFP

Background: People experiencing homelessness have significantly shorter life expectancies and higher rates of morbidity and mortality than the general population. Many barriers have been identified to providing palliative care to this population. This study examines health and social service providers' experiences providing end-of-life care to people experiencing homelessness, seeking recommendations to improve both patient and provider experience.

Methods: Qualitative study using phenomenological approach. Qualitative and quantitative surveys with 136 health and social service providers in Ontario's South East Local Health Integration Network, in-depth interview with 10 key informants.

Findings: Participants approached the end-of-life care of people experiencing homelessness from a framework of dignity and respect. Themes included barriers to end-of-life care internal to the health care system; care avoidance; the experience of stigma for this population when accessing end-of-life care; lack of provider information and awareness on how to provide care for marginalized groups, how to provide care in the context of substance use, and how to assist clients in accessing the formal palliative care system; and the need for harm reduction approaches to end-of-life care for persons experiencing homelessness.

Discussion: Focusing on harm reduction, and using the framework of Equity-Oriented Health Care to make systemic, cultural, and policy changes to develop a palliative-care system for persons experiencing homelessness may improve care experience for both patients and providers. ( $\mathrm{J}$ Am Board Fam Med 2019;32:847-857.)

Keywords: Harm Reduction, Health Care Disparities, Health Equity, Homeless Persons, Ontario, Palliative Care, Social Work, Surveys and Questionnaires, Terminal Care

The World Health Organization defines palliative care as "an approach that improves the quality of life of patients and their families who are facing

\footnotetext{
This article was externally peer reviewed.

Submitted 21 February 2019; revised 12 April 2019; accepted 16 April 2019.

From Street Health Centre, a part of Kingston Community Health Centres, Kingston, Ontario, Canada (MM); Department of Family Medicine, Queen's University, Kingston Ontario, Canada (MM, EP).

Funding: Funding for this project was received by the South East Local Health Integration Network (SELHIN) in Ontario, Canada.

Conflict of interest: none declared.

Corresponding author: Eva Purkey, MD, MPH, CCFP, FCFP, Queen's University, Department of Family Medicine, 220 Bagot Street, Kingston, Ontario K7L 3G2, Canada (E-mail: eva.purkey@dfm.queensu.ca).
}

See Related Article on Page 858. problems associated with life-threatening illness, through prevention and relief of suffering by means of early identification and impeccable assessment and treatment of pain and other problems, physical, psychosocial and spiritual." ${ }^{1}$ Access to equitable, nondiscriminatory health care is a human right in Canada and access to appropriate palliative care falls within these boundaries. ${ }^{2-4}$ That said, the current system on which palliative care in Ontario is based, namely that one has a home, a support network of family and friends, and access to a publicly funded health care system ${ }^{5}$ structurally and systematically excludes certain groups from care.

At least 235,000 Canadians experience homelessness in a given year, ${ }^{6}$ with 35,000 being homeless on any given night. Average life expectancy for homeless persons is between 42 and 52 years, with much higher rates of mortality than the general 
population. ${ }^{7,8}$ Homeless individuals often do not receive end-of-life care because of the challenges posed by their immediate environment. $44 \%$ to $60 \%$ of people who experience homelessness will use illicit substances in their lifetime. ${ }^{6,9,10}$ Despite a keen interest in advanced-care planning and specific preferences for location of death, homeless patients die in acute care hospital settings 34\% to $59 \%$ of the time. ${ }^{11,12}$ Many health care and social service providers feel that mainstream palliative care services are generally inaccessible to homeless populations and perhaps especially inaccessible to those who also use illicit substances. ${ }^{9,10}$

In this context, this study, funded by the South East Local Health Integration Network in Ontario, Canada, sought to explore palliative care among people who are homeless and/or vulnerably housed to improve programming and delivery of palliative care services. In this article, we report the findings from health and social service providers (HSSPs) on their experiences providing end-of-life care for persons experiencing homelessness. We also explore these topics in the context of substance use. We explore the barriers that service providers perceive to the delivery of appropriate palliative care, and the solutions they propose to improve equity in palliative care delivery for this particular population.

\section{Methods}

\section{Study Design}

This article derives from a mixed-methods study that explored the experiences of both HSSPs and people with a lived experience of homelessness. Data consist of surveys distributed widely to HSSPs, key informant (KI) interviews with HSSPs, and focus groups with people with lived experience. Data from these focus groups will be reported elsewhere. Data collection occurred between January and August 2018. This project was approved by Queen's University Health Sciences and Affiliated Teaching Hospitals Research Ethics Board.

\section{Participants:}

\section{Health and Social Service Providers Surveys}

A diverse sample of HSSPs was created, focusing on providers from organizations that act as a first point of contact for vulnerably housed persons (eg, Hospitals, home and community care providers, soup kitchens, Cancer Care of South Eastern Ontario, Community Health Centers, Street Health, mental health agencies, housing agencies, shelters, legal aid clinic, etc.). Survey responses, including both quantitative and qualitative data, were collected from 136 HSSPs to gauge providers' level of knowledge, comfort, awareness, and perceived barriers and knowledge gaps for palliative services and end-of-life care for those experiencing homelessness. Survey participants were recruited through mass emails, as well as targeted emails sent out to key partners.

\section{KI Interviews}

Based on the findings from our qualitative survey, specific HSSPs were approached for in-depth interviews as KIs. Relevant community agencies were asked to identify the most appropriate person(s) to interview. Other health care professionals were approached based on the information obtained in prior interviews. Inclusion criteria for KIs included informed consent, employment in their position for at least 1 year, employed in the specific community for at least 1 year, and provided front-line services directly to clients/patients (currently or in the past). KIs were a mix of urban, rural, and semirural HSSPs as self-reported by participants, to ensure a variety of perspectives. Final KIs interviewed included people from the following disciplines: paramedics, palliative care nurse practitioners, municipal government, community-based social services, housing and shelter system, spiritual care, harm reduction, and hepatitis $\mathrm{C}$ care. Indepth interviews with $10 \mathrm{KI}$ occurred either in-person or by telephone and explored emerging themes from the surveys using a semistructured research guide. Four themes were explored: barriers/challenges facing homeless persons' access to palliative care services, impact of substance use on service access, training/education and resources required to support population, recommendations for system change. Interviews lasted between 30 and 90 minutes.

\section{Data Analysis}

Quantitative survey data are reported below. KI interviews were audio-recorded and transcribed verbatim. Interview transcripts and qualitative data from provider surveys were imported into NVivo12 (QSR International, Burlington, MA). All data were read in its entirety and encoded using 
thematic analysis into key conceptual themes by 2 separate researchers (MM and EP), family physician researchers with experience working with equity seeking populations. Coding and themes were then compared and reviewed to ensure validity. ${ }^{13}$ Analysis was informed by a phenomenological approach, with researchers positioning themselves as advocates for improved end-of-life care for people experiencing homelessness.

\section{Findings}

\section{Quantitative Data: Demographic and Organizational} Data

136 HSSPs completed the survey (Table 1). Due to sampling methodology, this is a convenience sample and response rate cannot be calculated. Of respondents, $57 \%$ were from urban communities; $85 \%$ reported working in health care services or public health, and $76 \%$ in various social services, with obvious significant overlap between the 2 ; $74 \%$ indicated that their organization provided care to persons experiencing homelessness or vulnerable housing; $89 \%$ indicated that their organization provided care to people with substance-use disorders.

\section{Qualitative Data: Surveys and KI Interviews}

Themes from the qualitative data from HSSPs have been organized into 2 broad categories: 1) those pertaining to the barriers either they or their clients experience when trying to access end-of-life care (4 themes), and 2) those that reflect the gaps in knowledge, approaches, and services that could otherwise enhance their clients' access to care ( 3 themes). A third category, which deserves to be mentioned here but which will not be explored in more depth, is a small but important message highlighting the excellent service that palliative care professionals did generally provide for clients in the rare instances in which they are actually connected to services.

\section{Category One: Barriers to Accessing End-of-life care (Table 2)}

Theme 1: Structural Barriers to Care Outside of the Health Care System (Table 2)

Homelessness itself presents a host of barriers to accessing services, perhaps worse within the context of end-of-life care. Participants identified the most fundamental gap as the lack of a home or secure place of residence in the context of a palli-
Table 1. Demographic and Organizational Characteristics with Respect to Provision of Palliative Care

\begin{tabular}{|c|c|}
\hline Characteristics & $\begin{array}{l}\text { Responses, } \\
\%(\mathrm{n}=136)\end{array}$ \\
\hline \multicolumn{2}{|l|}{ Type of Community } \\
\hline Urban & 57.35 \\
\hline Rural & 24.26 \\
\hline Semirural & 18.38 \\
\hline \multicolumn{2}{|l|}{ Organizational sector (check all that apply) } \\
\hline Health Care & 74.26 \\
\hline Public Health & 11.03 \\
\hline Harm reduction & 20.59 \\
\hline Food assistance & 10.29 \\
\hline Housing assistance & 13.24 \\
\hline Social services & 19.12 \\
\hline Family and child services & 4.41 \\
\hline Community development & 8.09 \\
\hline \multicolumn{2}{|l|}{ Populations served } \\
\hline Homeless & 74.07 \\
\hline Persons with substance use disorders & 88.89 \\
\hline Indigenous people & 82.22 \\
\hline Veterans & 68.15 \\
\hline $\begin{array}{l}\text { Other-Including living with HIV; MSM, } \\
\text { LGBTQ2SI+, refugees, newcomers, } \\
\text { recently released from incarceration, } \\
\text { developmental disabilities, seniors }\end{array}$ & 28.15 \\
\hline \multicolumn{2}{|l|}{$\begin{array}{l}\text { Frequency of personal interaction with people } \\
\text { experiencing homelessness }\end{array}$} \\
\hline Never & 8.15 \\
\hline Daily & 16.30 \\
\hline Weekly & 15.56 \\
\hline Monthly & 14.81 \\
\hline Yearly & 10.37 \\
\hline I don't know & 13.33 \\
\hline \multicolumn{2}{|l|}{$\begin{array}{l}\text { Palliative care services available in your } \\
\text { community }\end{array}$} \\
\hline Home visits & 73.53 \\
\hline Hospital inpatient & 72.79 \\
\hline Hospital outpatient & 47.79 \\
\hline Residential hospice & 29.41 \\
\hline Respite & 45.59 \\
\hline I don't know & 15.44 \\
\hline $\begin{array}{l}\text { Other-Medical aid in dying, nursing } \\
\text { support, equipment loan }\end{array}$ & 23.53 \\
\hline \multicolumn{2}{|l|}{ Palliative care provided by target organization } \\
\hline Yes & 59.56 \\
\hline No & 37.50 \\
\hline I don't know & 2.94 \\
\hline \multicolumn{2}{|l|}{$\begin{array}{l}\text { Population served by palliative care services in } \\
\text { target organization }\end{array}$} \\
\hline Homeless & 55.56 \\
\hline Persons with substance use disorder & 79.17 \\
\hline
\end{tabular}

Continued 
Table 1. Continued

\begin{tabular}{|c|c|}
\hline Characteristics & $\begin{array}{l}\text { Responses, } \\
\%(\mathrm{n}=136)\end{array}$ \\
\hline Indigenous persons & 81.94 \\
\hline Veterans & 72.22 \\
\hline $\begin{array}{l}\text { Others-Living with HIV, seniors, recently } \\
\text { released from incarceration }\end{array}$ & 27.78 \\
\hline \multicolumn{2}{|l|}{$\begin{array}{l}\text { Palliative care services provided by target } \\
\text { organizations }\end{array}$} \\
\hline Advanced care planning & 75.00 \\
\hline Caregiver support & 61.84 \\
\hline Case management/patient navigator & 61.84 \\
\hline Emotional/psychosocial & 81.57 \\
\hline Medical management & 81.57 \\
\hline Spiritual support & 44.74 \\
\hline $\begin{array}{l}\text { Other-Hospitalization, primary care, } \\
\text { bereavement support, equipment loan, } \\
\text { physiotherapy, occupational therapy, } \\
\text { respite care, pharmacy }\end{array}$ & 22.37 \\
\hline \multicolumn{2}{|l|}{$\begin{array}{l}\text { Locations of palliative care provided by target } \\
\text { organizations }\end{array}$} \\
\hline Home & 84.42 \\
\hline Hospital inpatient & 48.05 \\
\hline Hospital outpatient & 28.57 \\
\hline Residential hospice & 22.08 \\
\hline Respite & 19.48 \\
\hline Clinic/office & 51.95 \\
\hline Other-Long-term care facility, shelter & 20.78 \\
\hline \multicolumn{2}{|l|}{$\begin{array}{l}\text { Number of palliative care or end of life } \\
\text { consults completed in } 2017\end{array}$} \\
\hline 0 to 5 & 34.92 \\
\hline 6 to 10 & 11.11 \\
\hline 11 to 20 & 6.35 \\
\hline 21 to 30 & 6.35 \\
\hline $30+$ & 41.27 \\
\hline
\end{tabular}

HIV, human immunodeficiency virus; LGBTQ2SI+, lesbian, gay, bi-sexual, transgender, queer, intersex, two-spirited; MSM, men who have sex with men.

ative care system in which most services are home based. The absence of a home makes it immediately impossible for clients to access many services. While the shelter system could technically make up for this gap, it explicitly does not, with KIs clearly identifying that shelters do not want people dying in their care. Indeed, the current structure of the shelter system, in which residents are requested to leave often for most of the day, renders it inappropriate for someone at the end of life. A number of clients do have "homes" but there are barriers to the provision of palliative care as these spaces may be considered unsafe for health care providers either because they are unfit for human habitation, or due to the potential exposure to violence, substance use, or other unpredictable considerations. Finally, palliative-care services are not generally provided to clients who live in tents or other temporary dwellings.

In addition to a home, palliative-care services anticipate that the individual receiving care will be surrounded by friends and/or family who can assist with their care. Respondents identified that this is often not the case for the homeless or vulnerably housed person. While patients may have a good social network, these support people may not be in a position to advocate for them or to provide care, either due to their own personal challenges, or due to the discrimination they face when interfacing with the health care system. HSSPs reported several instances in which they were identified by community members as next of kin.

Finally, additional barriers to accessing services identified by respondents included lack of identification, lack of an Ontario Health Insurance Plan card, lack of a phone with which to receive calls about appointment times, and lack of transportation to make it to appointments.

\section{Theme 2: Systemic Barriers to Care Within the Health Care System (Table 2)}

Respondents identified many barriers within the current health care system. Barriers included the requirement that one have a family physician as a conduit to a referral to palliative care services, and the lack of continuity in the system for this population for whom trust is particularly important and difficult to establish. The geographic location of services, often far from the places where people live, was another barrier. An overall paucity of palliative care services, not specific to the homeless population, including a lack of sufficient hospice beds was identified. Finally, the rigidity of the existing system, the lack of a harm reduction approach or services, and the stigma with which people are treated, were the most important barriers deserving a theme of their own below.

\section{Theme 3: Care Avoidance (Table 2)}

Respondents identified many barriers internal to their clients which could be challenging to navigate. Most of these manifested as different forms of care avoidance. Clients avoided seeking care until very late in their disease, often when they were past the point of having choices around their palliative care. The struggles of day-to-day life for people 
Table 2. Category One: Barriers to Accessing End-of-Life Care

\begin{tabular}{ll}
\hline Theme & Quote \\
\hline
\end{tabular}

Theme 1: Structural barriers to care outside of the healthcare system

Theme 2: Systemic barriers to care within the healthcare system

Theme 3: Care avoidance

Theme 4: Stigma as a barrier
The government initiated preference seems to be in home services. However, the in-home service hours allotted to a dying individual seems to be a few hours per day; thus, putting the onus on family members. Unfortunately, homeless people do not have a home and they often lack family members who can help them. Also, homeless people may not know how to access end-of-life services and they may not have a primary health practitioner. (SR)

[the shelter system is] phenomenal and by no means am I saying that they're not doing great work. But the first thing that the case worker said to me when I was talking about this medical bed and would it be available for someone who was dying. They specifically said like yeah but we don't want them dying here. (KI 6)

I have a gentleman who has cancer and was told that he can't get treatment until he gets housing. So, how is that helpful? What if he was an individual that didn't want housing? So, you're never going to get treatment just because you choose that you don't want housing. That's not OK. (KI 2)

Her being in a hospital would mean her friends really couldn't come and stay because they would act inappropriately. There'd be a security person called. They'd be removed. I mean, this is the difficulty. So, she would really be cutting herself off, I think, from that sense of "I'm around the people who I love". (KI 4)

He was lonely. People that would ah that were kind of familiar with him, that would check on him and stuff for people, that kind of were part of that community and lived in the area, so it was easier for them, you know, with the lack of transportation to go and check up on him at his home. But then being transferred to [institution] - nobody could really access it or people that wanted to, had had such a negative experiences with main stream health care in the first place didn't want to be in that environment. (KI 1)

Depending on situation and substance used by specific patient and history of said use. If patient is actively using illicit substances and is regularly intoxicated during clinical encounters, there may be challenges related to communication, compliance, and arranging appropriate follow-up, along with financial challenges related to access, transportation, equipment, and medication costs (SR)

Many community programs are "home care" programs—-meaning you require a "home" to receive care. (SR)

Ah I think there's also, the other problem being the trust. They don't really trust the health care system because they haven't had best dealings for the most part with them, either hospital staff or physicians, and aren't as willing to follow through. (KI 7)

A person who is marginalized or substance using or are homeless just may not be able to focus on managing their illness because they're too busy focusing on the day to day stuff. Where they're going to stay. What they're going to eat. What they do for funding. That sort of thing. Being able to kind of see the long term is sometimes difficult and palliative care is partly about planning for that. [...] So, you know, I think generally what happens is they get sick to the point that they can't manage and then they end up in hospital and that's when they'll receive their palliative care support. (KI 1)

Addiction usually takes precedence over all other life choices. Acknowledging and incorporating drug use into end-of-life care in my opinion would increase engagement of these services. Banning drug use as a requirement for participation in these services would be a huge barrier to engagement. (SR)

I had a client that was palliative that would call every day crying saying that he could hear the staff talking about him (KI 1)

We're actually supporting a very young individual who is dying currently with very limited palliative resources that he is comfortable accessing. So it's not necessarily that they're not there, but when you use [substances] several times a day, you go to the hospital and they're not giving you the proper medication to keep you comfortable because your tolerance is so high. So you leave the hospital, but then they discharge you because you left against medical advice. So then they don't want to go back. It's kind of the cycle that that we've seen um with other clients in the past (KI 6) 


\begin{tabular}{|c|c|}
\hline Theme & Quote \\
\hline & $\begin{array}{l}\text { We have heard of tenants who have gone, you know, into the hospital for tests } \\
\text { and have been refused service because they were told they smelled. (KI 5) }\end{array}$ \\
\hline & $\begin{array}{l}\text { I can't fathom how difficult it must be to be trying to do your triage work in } \\
\text { emergency. Already demanding and then throw somebody who comes in, you } \\
\text { know, high on crystal meth. I make no criticism; however, I think that's a big } \\
\text { problem. I'll share a story that was shared with me. [This woman] had } \\
\text { suffered a brutal rape. Horrific. Absolutely horrific. She was a woman in her } \\
\text { late } 40 \text { s. Lived on the street throughout her whole life, back and forth. She } \\
\text { was telling me her story. She needed to share it [...] and she didn't cry. Not } \\
\text { one tear when she talked about the abuse that she endured [..]. She wept } \\
\text { when she talked about how she got treated at the hospital because she was } \\
\text { bleeding so profusely and she flinched at a needle and the comment from the } \\
\text { nurse was made to her: "Well look at your arms, as if you have a problem } \\
\text { with needles". That weighed so heavily and this is when the woman broke } \\
\text { down. The abuse was horrific but she had almost been marinating in that } \\
\text { level of violence and abuse all her life. The devastating part of it all was the } \\
\text { shame she felt from the hospital. I just I remember thinking: Holy smokes. } \\
\text { Do we ever have a problem here? If what this man did to her- horrify and it's } \\
\text { certainly impactful on her but that's not what broke her. What broke her was } \\
\text { being so dismissed in hospital because of her I.V. drug use. Yeah. So, you } \\
\text { know that's an example of an off the cuff remark made by somebody who I } \\
\text { guarantee you had no intention of hurting a woman. (KI 4) }\end{array}$ \\
\hline & $\begin{array}{l}\text { So it starts off a negative experience right from the get-go. And generally people } \\
\text { don't even stay. I had a client years ago that ended up ah being very unwell. I } \\
\text { took him to the hospital. I stayed with him which was fine. People generally } \\
\text { are nicer if you have somebody to advocate for them. But as soon as he was } \\
\text { admitted into the hospital he ah was treated very poorly by staff. He ended up } \\
\text { leaving and he ended up dying in [name of] park by himself. (KI 10) }\end{array}$ \\
\hline
\end{tabular}

KI, key informant; SR, survey respondent.

experiencing homelessness often took precedence over seeking out palliative care. Care avoidance also related to extremely negative experiences of the health care system related to stigma that clients had experienced in the past. Another cause for service avoidance was substance use. Not only would clients avoid services that they knew could not or would not accommodate their substance use, but substance use became a top priority for clients, superseding the potential importance of health care or palliative care in their minds. Finally, clients struggled to conform to the current system, resulting in avoidance behaviors such as not waiting long enough in the emergency department to be seen, or leaving if they felt that their needs were unmet or that they were being judged.

\section{Theme 4: Stigma as a Barrier (Table 2)}

Stigma as a barrier crosses all the previous themes. According to our respondents, stigma manifested in health care providers not taking into account patients' lived realities when considering recommended courses of action (see theme 1); in overt discrimination, rude or thoughtless behavior toward their clients (see theme 2); and finally resulted in care avoidance due to negative past experiences on the part of service users (see theme 3). Stigma was worse in the context of a client with a substance use disorder. The consequences of stigma included the exclusion of support networks for hospitalized patients (support networks, often drawing from similar social situations as the patient, were either made to feel unwelcome or in some cases explicitly asked to leave) resulting in patients having to make the decision to leave or to die alone in hospital; denial of care (for example, patients who "refused" to stop their illicit substance use might have care withdrawn or refused); and could result in patients feeling so frustrated and/or unwelcome that they would leave "against medical advice" even if this meant they were at risk of dying on the street.

\section{Category 2: Unmet Needs: Gaps in Knowledge, Services, and Approaches Needed to Enhance End-of- Life Care (Table 3)}

\section{Theme 5: Comfort with Providing Care to Those} Experiencing Homelessness (Table 3)

All the KIs and many of the HSSPs who responded to the survey indicated that they were comfortable providing care to homeless or vulnerably housed 
Table 3. Category Two: Unmet Needs: Gaps in Knowledge, Services and Approaches needed to Enhance End-of-Life Care

Theme
$\begin{aligned} & \text { Theme 5: Comfort with providing care to } \\ & \text { those experiencing homelessness }\end{aligned}$

Theme 6: Gaps in healthcare provider knowledge and/or attitudes

Theme 7: Gaps in available services and possible solutions

\section{Quote}

Like if you don't think that you can set your judgements aside then you shouldn't be working with these individuals, right? [...] And if you're going to cause more harm than good for the individual because you can't set your judgements aside and understand that you took an oath to provide care, then you need not to be working with those individuals. That to me is so so so important. (KI 10)

They're invisible. So, for me it's an exciting place to work because these rough looking people but these beautiful spirits come out and their ability to survive. [..] You know it's all those kids we think about when we hear these horrific news stories of abuse. They went into the foster care system and then we don't think of them again but that little kid ends up being the 30 -year-old with a criminal record and that little kid ends up being a woman who's prostituted for the last 10 years. (KI 4)

I believe that staff and volunteers would benefit from specified training and development—substance dependency, trauma, other mental health issues, etc. (SR)

Compassion training, substance abuse training, harm-reduction training. More of an intensive like mental health training, um, de-escalation-lots of things, you know. Lots of things. (KI 10)

Oh we have to start changing the social construct of how we view individuals who use substances, who are homeless, who are suffering with mental health issues. If we don't change our views on how we see these individuals - that they are the root cause of all their problems-then I don't think anything will change. (KI 10)

Probably just having a list of services available in the city that you can give them. Like that we can jot down on a piece of paper for them or numbers that we can give them for them to get in contact with the proper people if the hospital doesn't um provide it. And if we had a bit of an idea of what was available I'm sure most of us would at least talk to them about it. (KI 7)

It would be nice to have a space that we could provide for individuals that are palliative that is staffed and supported by individuals who have worked with people with chronic substance use, chronic mental health, the homeless, transient population - that have an understanding and can provide respectful, dignified care (KI 10)

We operate out of fixed locations or we operate, you know, at fixed addresses and I think that needs to change. I think, you know, we have a very high percentage of homelessness. And I feel that we need to maybe change some of the ways we're doing things to accommodate people who are unstably housed or living on the street or living at tent city or. I think we should have more outreach, palliative outreach. (KI 6)

I could envision an opportunity to even have some of our clients, who were maybe more leaders in this community, getting some training and being able to provide that themselves. [... Peer support. I think that can be really powerful because there is this kind of kickback against anything they view as authoritative. (KI 4)

A harm reduction approach will always provide more options for an individual using illicit substances. If they know that care will still be provided to them in a nonjudgmental way, and in an environment that will address and support them with this issue, they are much more likely to access these services. (SR) 
care providers. Many suggested the need for enhanced health care provider training on trauma, addictions and mental health, empathy, and respectful approaches to persons experiencing substance use or homelessness.

In addition, respondents, many of whom were not health care providers, indicated a need for a better understanding of the existing palliative care system and how to access it for their clients. Participants discussed the need to have the ability to refer within this system, even if they are not physicians, as they may be the only professional their clients engage with.

Finally, respondents articulated a need for better education regarding the provision of end-of-life care for people using substances, citing the importance of safety, legality, and drug interactions as areas where information was needed.

\section{Theme 7: Gaps in Available Services and Possible Solutions (Table 3)}

Several gaps in existing services were articulated. More hospice beds are needed, and these need to be more flexible, comfortable, and accessible to the preferences of people experiencing homelessness. Participants cited outreach services in other communities that they perceived could be helpful to their clients, rather than insisting that they fit into the new current ambulatory mold. Finally, and most importantly, a palliative care system that embraced the principles of harm reduction was perceived to be essential to allow clients to enter into care, and to remain in care that preserved their dignity. Participants felt it was unreasonable and unnecess-

ary to expect people to renounce their substance use at the very end of their lives, and problematic that this was often necessary for them to receive any type of institutional care.

\section{Discussion}

Our initial hypothesis was that people experiencing homelessness, particularly those using substances, experience more barriers to accessing palliativecare services, and that developing a system of care that is trauma informed, culturally sensitive, and rooted in a harm-reduction philosophy would improve health equity in the context of end-of-life care. Many of the barriers in our study have already been identified in the literature, ${ }^{9,10,14}$ including the more significant barriers for clients who use substances. We would like to focus on 2 important findings for further discussion and recommendations.

The first finding we would like to address is the view among participants that a palliative care system developed around a harm reduction approach is key for this population, both in terms of allowing them to access care without giving up their substance use, and expanding available options to ensure that "choice" is one of the core components of an end-of-life care approach. Returning to the world health organization (WHO) definition of palliative care focused on improving the quality of life of patients through prevention and relief of suffering, we propose that forcing people to give up their substance use, (for some a source of secure attachment), to potentially go through unpleasant withdrawal, and to be disconnected from their support networks through rendering services unwelcoming to these networks does not meet this standard. Canada currently has legalized supervised injection sites in 4 provinces, ${ }^{15}$ and legislative changes could be made to allow this in hospitals, hospices, or other palliative-care settings as well. Our findings indicate that ideal services and facilities must be comfortable, accessible, and welcoming for families/friends, offering choice and collaboration, and staffed with people familiar and experienced with working with equity-seeking populations. We recommend formal integration of people with lived experience into the palliative-care system, with appropriate compensation and recognition of their unique expertise as a way to meet this objective. Finally, participants indicated that future programs must consider outreach to homeless populations, both to the places where they live and to the places where they are already receiving services, rather than insisting they fit into the current paradigm of on-site or in-home service delivery. This would involve extending hours of care and supporting HSSPs to provide palliative care in community organizations and shelters, with the necessary changes to these facilities to accommodate the needs of people at the end of their life. It would also involve better integration between social and health care services and the creation of systems that support providers to safely offer care in nontraditional living spaces such as tents, on the street, and in substandard housing among others. 
Figure 1. Logic model for improving end of life care for the homeless and vulnerably housed.
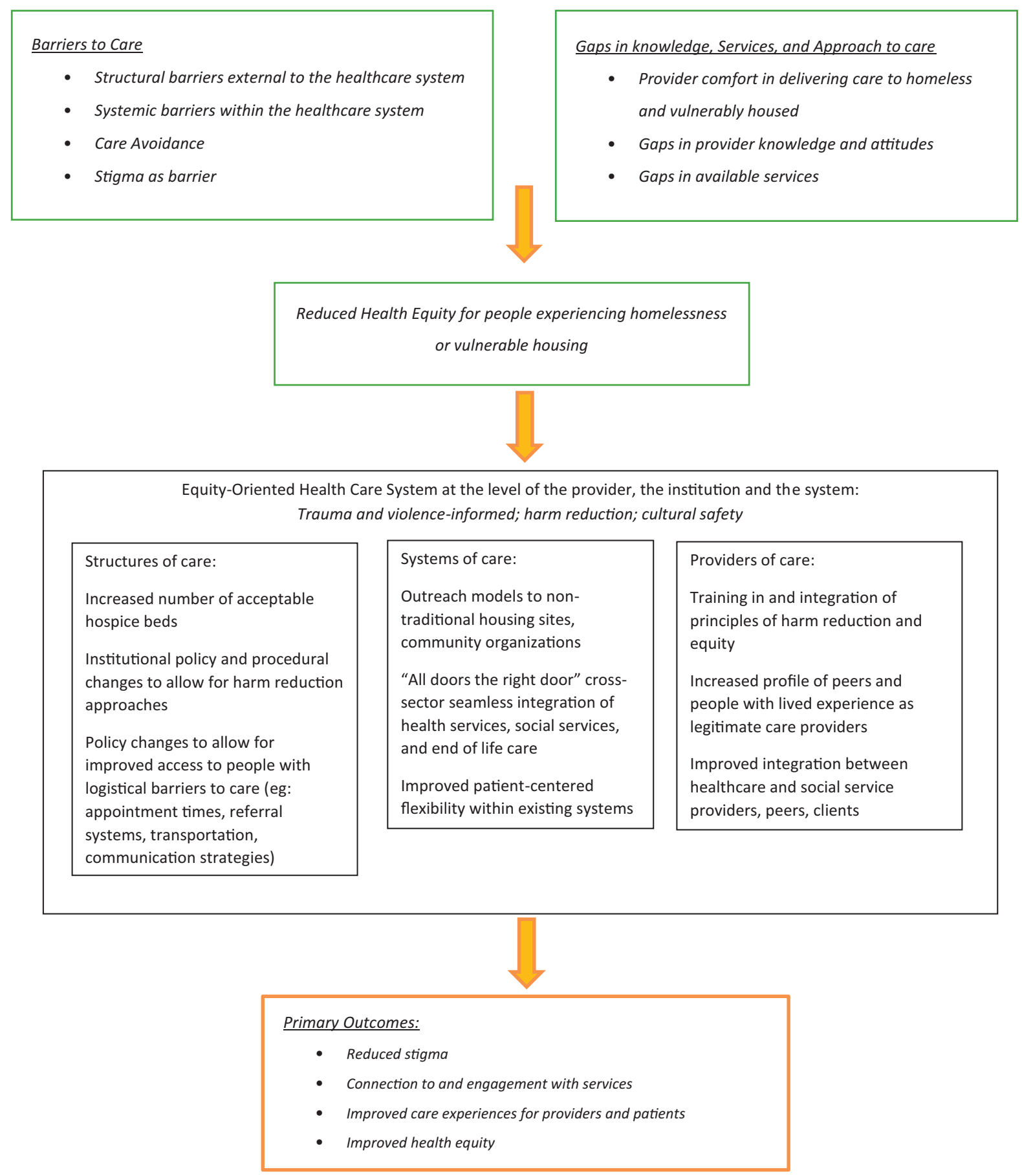

The second finding is the fundamental relationship between ongoing stigma within the health care system, and the care avoidance demonstrated by people who are vulnerably housed. While some of this care avoidance may be related to other aspects of personal preference, most of it seems to be tightly linked to the negative experiences of home- less clients within the health care system. Participants had many examples of the stigma experienced by their clients throughout the system. That stigma is a problem for equity-seeking populations within the health care system is well documented. ${ }^{16-21}$ Whereas many of the changes needed to meet the recommendations in the previous paragraph focus 
around system changes and legislation, the changes required to reduce stigma involve deeper, sometimes more difficult, cultural and belief changes for the individuals working within the system. The HSSPs in our study have many suggestions centering on sensitivity training, harm-reduction training, and equity training for health care workers. Equity-Oriented Health Care (EOHC) is a model of care that uses a multi-pronged approach (eg, education, strengths, weaknesses, opportunities, and threats (SWOT) analysis, additional funding to promote system change, all adapted to context) focused on 3 aspects of care, namely 1) trauma and violence informed care, 2) harm reduction, and 3) cultural safety, to create health systems that are designed to enhance equity. ${ }^{22,23}$ Education on its own is necessary but not sufficient to change a system and providers bound by institutional policies and procedures, as well as a deep culture of health care, none of which have equity or harm reduction as their focus. All members of an organizational team need to engage with personal and system change, altering the "middle class" lens of the health care system to create people and systems that understand the impact that poverty and addiction, among others, have on access to health care services, including palliative care. Redesigning health and social systems with EOHC as a focus can lead to changes in HSSPs perceptions of themselves and of clients and can open up heretofore unimagined possibilities for system change. The logic model proposed in Figure 1 outlines only some ideas of how our system needs to change to decrease embedded stigma and improve health equity.

\section{Limitations}

One limitation of our study is the apparent absence of the perspective of HSSPs who feel strongly against providing harm reduction- and/or traumainformed approaches in the context of palliative care for persons experiencing homelessness. This is partially a function of our sampling strategy. The survey is a convenience sample, since surveys were optional and sent out widely by organizational contacts. Response rates cannot be calculated, and it is likely that survey respondents were more likely to be positively predisposed toward, or at least interested in this population. Our KI interviews were selected by purposeful sampling; however, a negative perspective on the provision of care for homeless and vulnerably housed was not a selection cri- teria. Obviously, given the rates of stigma reported by our participants, such providers exist; however, as is often the case in such studies, their voices are not heard in these findings. This is an important omission, since it is through an understanding of their differing perspectives and experiences that we can hope to bridge the gap between patient and provider in a way that meets the needs of both.

\section{Conclusion}

"Lack of access to end-of-life care is the final indignity these people encounter." (SR)

To achieve equitable access to services for people requiring palliative care who are homeless and may use substances we will need to change the focus of our health care and end-of-life system to enhance training, awareness, and systems related to best practices in working with equity-seeking populations. Our system must begin to focus on equity of outcome rather than equality of service provided. Interventions must be flexible and adaptable, involving staff delivering front-line services as well as peer experts, and requiring organizations to review their policies and practices when working with equity-seeking populations. One potential option that could address these important themes expressed by HSSPs would be to pursue EOHC, a proven approach that aims to address barriers to health equity. This approach emphasizes the need to adapt to local context, and to engage with providers who are both committed to, and those who are more resistant to, the principles underlying a health equity approach. It also requires re-envisioning systems, policies, and procedures with equity in mind. Incorporating an EOHC approach into health and social service settings will improve both provider and patient experiences. ${ }^{22-22} \mathrm{~A}$ phase-II study could look at implementing this approach and assessing outcomes within our health care system.

The authors thank the research assistants (Megan Singh, Agniesczka Fecica, Travis Mitchell, Amanda Brierly, Regan Lavoie), and Dr Alex Leung for study design feedback. Lastly, thank you to the participants who agreed to share their stories to shape our understanding.

To see this article online, please go to: http://jabfm.org/content/ 32/6/847.full. 


\section{References}

1. World Health Organization. WHO Definition of palliative care. Available from: https:/www.who.int/ cancer/palliative/definition/en/. Accessed Feb 18, 2018.

2. Baker DC, Cross G. Establishing the right to palliative care in Canada. September 13, 2017. Available from: https://www.bakerlaw.ca/wp-content/uploads/ Establishing-A-Right-to-Palliative-Care-in-Canada.pdf.

3. Gwyther L, Brennan F, Harding R. Advancing palliative care as a human right. J Pain Symptom Manage 2009;38:767-774.

4. Brennan F. Palliative care as an international human right. J Pain Symptom Manage 2007;33:494-499.

5. Henry B, Dosani N, Huynh L, et al. Palliative care as a public health issue: understanding disparities in access to palliative care for the homeless population living in Toronto, based on a policy analysis. Curr Oncol 2017;24:187-191.

6. Roy E, Boudreau JF, Leclerc P, et al. Trends in injection drug use behaviors over 10 years among street youth. Drug Alcohol Depen 2007;89:170-175.

7. Gaetz S, Dej E, Richter T, Redma M. The state of homelessness in Canada 2016. Toronto, Canada: Canadian Observatory on Homelessness Press; 2016.

8. Huynh L, Henry B, Dosani N. Minding the gap: access to palliative care and the homeless. BMC Palliat Care 2015;14:62.

9. McNeil R Guirguis-Younger M. Illicit drug use as a challenge to the delivery of end-of-life care services to homeless persons: Perceptions of health and social services professionals. Palliat Med 2012;26:350-359.

10. Grinman MN, Chiu S, Redelmeier DA, et al. Drug problems among homeless individuals in Toronto, Canada: prevalence, drugs of choice, and relation to health status. BMC Public Health 2010;10:94.

11. Health Quality Ontario. Palliative Care at the End of Life 2016. 2016. Available from: https:// www.hqontario.ca/Portals/0/documents/systemperformance/palliative-care-report-en.pdf.

12. Dosani N. Living \& dying on the streets: towards palliative care equity for the homeless \& vulnerably housed in Ontario public lecture 2017.

13. Creswell JWP, Cheryl N. Qualitative inquiry and research design. Thousand Oaks, CA: SAGE Publications; 2018.

14. Klop HT, de Veer AJE, van Dongen SI, et al. Palliative care for homeless people: a systematic review of the concerns, care needs and preferences, and the barriers and facilitators for providing palliative care. BMC Palliat Care 2018;17:67.

15. Government of Canada. Supervised consumption sites: status of applications. Available from: https:// www.canada.ca/en/health-canada/services/sub- stance-use/supervised-consumption-sites/statusapplication.html. Accessed April 12, 2019.

16. Bauer GR, Scheim AI, Deutsch MB, et al. Reported emergency department avoidance, use, and experiences of transgender persons in Ontario, Canada: results from a respondent-driven sampling survey. Ann Emerg Med 2014;63:713-720.e1.

17. Chisolm-Straker M, Jardine L, Bennouna C, et al. Transgender and gender nonconforming in emergency departments: a qualitative report of patient experiences. Transgend Health 2017;2:8-16.

18. Dubin RE, Kaplan A, Graves L, et al. Acknowledging stigma: its presence in patient care and medical education. Can Fam Physician 2017;63:906-908.

19. Wylie L, McConkey S. Insiders' insight: discrimination against indigenous peoples through the eyes of health care professionals. J Racial Ethn Health Disparities 2019;6:37-45.

20. Wen CK, Hudak PL, Hwang SW. Homeless people's perceptions of welcomeness and unwelcomeness in healthcare encounters. J Gen Intern Med 2007;22:1011-1017.

21. Skosireva A, O'Campo P, Zerger S, et al. Different faces of discrimination: perceived discrimination among homeless adults with mental illness in healthcare settings. BMC Health Serv Res 2014;14:376.

22. Browne AJ Varcoe C, Ford-Gilboe M, Wathen CN. EQUIP Healthcare: An overview of a multi-component intervention to enhance equity-oriented care in primary health care settings. Int J Equity Health 2015;14:152.

23. EQUIP Health Care. What is health equity: a tool for health \& social service organizations and providers. 2017.

24. Ford-Gilboe M, Wathen CN, Varcoe C, et al. How equity-oriented health care affects health: key mechanisms and implications for primary health care practice and policy. Milbank Q 2018;96:635-671.

25. EQUIP Health Care. Key dimensions of equityoriented care: 10 strategies to guide organizations in enhancing capacity for equity-oriented health care. 2017. Available from: https://equiphealthcare.ca/ equip/wp-content/uploads/2017/12/Key-Dimensions-Dec-13-2017.pdf.

26. EQUIP Healthcare. Promoting Health EquityHarm Reduction. 2018. Available from: https:// equiphealthcare.ca/equip/wp-content/uploads/ 2018/04/HRT-Apr-17-2018.pdf.

27. EQUIP Emergency. Promoting health equity for indigenous and non-indigenous people in emergency departments in Canada: Project Summary 2018. Available from: https://equiphealthcare.ca/equip/ wp-content/uploads/2019/06/EQUIP-ED-projectsummary_20Jun2019.pdf. 